\title{
Philanthropy Competition Builds Community Among Honors Freshmen
}

\author{
Melissa L. Johnson
}

The Honors Program at the University of Florida offers 6-7 sections of a professional development course for first-year students each fall semester. The goal of the course is to connect first-year honors students to campus and community resources. One such way we connect our students to the broader community is through a philanthropy competition held each fall semester. This paper outlines the fundamental aspects of our professional development course, followed by a detailed description of the philanthropy competition.

Each section of our professional development course is limited to 25 students and is not required by the Honors Program. In this 1-credit elective course, students work closely with an honors advisor and a current honors student leader to develop an action plan for university involvement. Students learn how to find and apply for scholarships and awards, internships, study abroad programs, research opportunities, and leadership and service projects.

The course objectives include helping students become familiar with opportunities for academic involvement, such as undergraduate research, internships, and international experiences. Students also learn to begin applying the knowledge gained in the course into practice and to develop skills in writing, oral presentation, and teamwork. They develop practical skills in writing resumes, effective interviewing, understanding academic documents such as degree audits, and working with faculty. Lastly they build a positive mentoring and working relationship with their honors advisor and peer leader.

Course highlights include panels on undergraduate research, study abroad, and internships. Honors students who have participated in these opportunities are invited to participate on the panels to share the nuts and bolts of how they found these opportunities, what the experiences entailed, and what they gained from these experiences. Students also participate in three workshops on resumes, mock interviews, and academic advising prior to course registration for the following semester.

When initially designing a first-year experience course for honors students in 2005, we wanted to help build community among all of the sections that we offered. One of the ways in which we could do so was through a joint community service activity with students in all of our sections during the semester. While the service project worked fairly well the first year we offered it, we ran into a few snags in 2006. Just a couple of weeks prior to the service project date in November, the

Melissa L. Johnson (mjohnson@honors.ufl.edu) is an Assistant Director of University Honors Program at the University of Florida. 
project fell through. With only a few weeks remaining in the semester, we scrambled to coordinate a new project. Thus, the Honors Superchallenge was born. We piloted the Superchallenge with two sections of our course in Fall 2006. The Honors Superchallenge capitalized on the competitive nature of our students. We took the wish list on the Web site of the Girls Club of Alachua County and assigned point values to each item (see Table 1). For example, a pack of 10 pencils was worth 1 point, while a playground ball was worth 5 points. Each student had to collect at minimum 5 points worth of items for the Girls Club. Since two-thirds of the Superchallenge team score was composed of the points collected for the Girls Club, students wanted to collect as many items as possible to remain competitive in the challenge.

I was first introduced to the Girls Club when I advised a women's leadership group that had adopted them as their philanthropy. The Girls Club of Alachua County provides recreational activities for young girls in a safe and fun environment. Girls have the opportunity to participate in sports, specialty classes, and summer camp activities. Girls who participate in these programs come from diverse backgrounds, and the Girls Club receives referrals from state and local agencies such as the Department of Children and Families.

The students brought all of their items to the Superchallenge Field Day on a Sunday afternoon in early December. The items were compiled and point totals assigned, although the classes were not told their final scores. From there the two sections competed in a field day competition, harkening back to elementary school tug-of-war contests, wheelbarrow races, and egg-and-spoon relays. Students won additional points for their team score based on their finish in each field day event. The field day took place behind the honors residence hall and lasted two hours. At the end of the field day, the teams were told their final rankings in the Superchallenge, and the winning section won a bowling party at the campus bowling alley.

At the conclusion of the first Superchallenge, the students were sweaty and exhausted, but completely energized and enthusiastic about what had just happened. Not only had we achieved a little community spirit, we also had collected hundreds of items for the Girls Club. A last-minute event planned as a substitute for a canceled community service project ended up wildly successful. Students wrote on their final course reflections that the Superchallenge had been one of the best parts of the class that semester. Although we knew we were going to continue offering a traditional community service project in future semesters, we made the decision to continue offering the Superchallenge as well.

During Fall 2007, the Superchallenge competition expanded to three sections of the course. Two additional sections made participation in the event optional. The event took place in November, just prior to the Thanksgiving. Because students brought so many donations for the Girls Club to the field day event, the peer leaders for each section helped tally items. With more teams competing in the field day, there was an even greater energy on the field and more cheering and support among classmates. Some students even chose to wear team colors to represent their sections. At the conclusion of the second annual Superchallenge, we had collected 
hundreds more items for the Girls Club.

By this time, we felt as though we could expand the Superchallenge to all six sections of our course. We had worked out most of the logistics with the prior two events and felt comfortable inviting everyone to participate. Superchallenge III took place in November 2008. This time we gave the students the week prior to the field day to deliver their items for the Girls Club to our office. Because two-thirds of the final team score is based on the items collected, in the prior two years the students were able to figure out who would win the Superchallenge after they saw which class had brought the most donations to the event. By collecting the items in advance, no one knew which class was ahead leading up to the field day. This change added much more suspense when it was time to announce the winner at the conclusion of the field day.

Nearly 120 students participated in Superchallenge III- three times as many students than had participated in the original event. All of the peer leaders and instructors participated. Each class selected a team color and showed up to the field day dressed in their colors. One section even painted their faces and hair to match their team color. With so much energy among these students, the field day was electric. For two hours the students fought through the competition, concluding with an epic coed tug-of-war battle between the last two sections standing. Students in sections that did not make the finals of the event often rallied around another section in the finals to show their support.

The number of items donated to the Girls Club this past year was overwhelming. We stored the items in an empty cubicle in our office throughout the week prior to the field day. The items quickly piled up and began to spill out into the hallway. The staff and girls at the Girls Club have been very appreciative of all of the items collected for them these past three years. Their wish list has included practical items, educational resources, craft supplies, and fun games. We have been able to donate articles from all of those categories.

When we first started the Superchallenge, we needed a quick substitute for a canceled community service project. We noticed that even with only a third of our sections participating at the time, there was a potential for a major community-building event. The benefits to the Girls Club created a win-win situation for everyone involved. After three years of organizing the Superchallenge, we plan to keep it as a permanent part of our course. With all sections of our course now participating, the Superchallenge has become an important component of our fall semester. The event has not cost our office anything but time to coordinate as we are able to reserve any equipment needed for the field day through our department of recreational sports. It is a simple, yet highly effective event benefiting multiple constituencies that can easily be replicated in other programs. 


\section{Summary of Girls Club Collection Items and Point Values}

Point Value

1

2

3
Collection Item

10 pencils or pens

5 packs of embroidery string

Glue bottle or stick

Bag of balloons

10 packets of seeds for a garden

Tempera or poster paint - per color

Markers - per box of 8

Crayons - per box of 24

Construction paper - per package

Scissors

Chalk - sidewalk or board - per box or package

Deck of playing cards

Bag of cotton balls

Packet of beads

Lanyard string

Knitting needles - per set

Hula Hoop

Jump rope - long double-dutch style

Big bouncy balls

Box of Band-Aids ${ }^{\circledR}$

Roll of athletic tape

Tube of antibiotic ointment or anti-itch cream

Bottle of eye drops

2 pairs of kid-size socks

Small box of Legos ${ }^{\circledR}$

Building blocks

Lincoln Logs

Kickball or soccer ball - size 3, 4, or 5

Board games for a limited amount of players

Dictionary with more than 300,000 entries

Thesaurus with more than 150,000 entries

Box of flash cards - math and reading 